\title{
The effect of temperature during culture enrichment on
}

\section{methanotrophic polyhydroxyalkanoate production}

1

2 Rebeca Pérez ${ }^{1,2}$, Sara Cantera ${ }^{1}$, Sergio Bordel $^{1,2}$, Pedro A. García-Encina ${ }^{1,2}$, Raúl

$3 \mathrm{Muñoz}^{1,2} *$

4

5 1-Department of Chemical Engineering and Environmental Technology, School of

6 Industrial Engineerings, Valladolid University, Prado de la Magdalena,5, Valladolid, Spain,

$7 \quad$ Tel. +34 983186424, Fax: 983423013 .

8 2- Institute of sustainable processes, Valladolid University, Spain

$9 \quad$ Author for correspondence: mutora@iq.uva.es

10 


\section{Abstract}

12 Climate change and plastic pollution are likely the most relevant environmental problems 13 of the $21^{\text {st }}$ Century. Thus, one of the most promising solutions to remedy both 14 environmental problems simultaneously is the bioconversion of greenhouse gases, such as 15 methane $\left(\mathrm{CH}_{4}\right)$, into bioplastics (PHAs). However, the optimization of this bioconversion 16 platform is still required to turn $\mathrm{CH}_{4}$ biotransformation into a cost-effective and cost-

17 competitive process. In this context, the research presented here aimed at elucidating the 18 best temperature culture conditions to enhance both PHA accumulation and methane 19 degradation. Six different enrichments were carried out at 25,30 and $37^{\circ} \mathrm{C}$ using different 20 inocula and methane as the only energy and carbon source. $\mathrm{CH}_{4}$ biodegradation rates, 21 specific growth rates, PHA accumulations and the community structure were characterized. 22 Higher temperatures $\left(30\right.$ and $\left.37^{\circ} \mathrm{C}\right)$ increased the PHAs accumulation up to $30 \%$ regardless 23 of the inoculum. Moreover, Methylocystis became the dominant genus $(\sim 30 \%$ of the total 24 population) regardless of the temperature and inoculum used. This research demonstrated 25 for the first time the fundamental role of temperature in increasing both the accumulation of 26 PHAs and methane abatement during the enrichment of PHA cell-factories from methane, 27 thus enhancing the cost-effectiveness of the process.

\section{Keywords:}

29 Bioplastics, Greenhouse Gas Abatement, Methanotrophs, PHA, methane. 


\section{Introduction}

32 Nowadays, the two most important environmental issues that our society is facing are

33 Climate Change and Plastic Pollution. In this sense, novel industrial strategies are

34 necessary to abate toxic greenhouse gasses (GHG) and to substitute current used plastic materials without compromising present economic and industrial development. Methane $\left(\mathrm{CH}_{4}\right)$ is currently the second most important GHG (Desai and Harvey, 2010) and

37 its atmospheric concentration continues to rise at a yearly rate of 0.2 to $1 \%$ mainly due to 38 anthropogenic activities (agriculture, livestock, waste management and energy production) 39 which has caused growing interest, from a political and a scientific point of view, in 40 greenhouse gas abatement ((EPA), 2017). On the other hand, the massive usage of plastic 41 products and poor management of waste disposal has resulted in microplastic 42 contamination of bodies of water, which injures wildlife through entanglement or ingestion 43 of plastics and through the toxic and carcinogenic effect of some polymers. Additionally, it 44 has been demonstrated that plastics can make their way up the food chain, causing similar

45 health threats to humans. This situation has encouraged an intensive research to find and 46 produce biodegradable and non-toxic plastics or biopolymers, such as 47 polyhydroxyalkanoates (PHAs) which could definitively substitute and end the use of 48 pollutant plastics (Löhr et al., 2017; Pieja et al., 2017; Sigler, 2014).

49 The PHAs are synthesized under nutrient-limited and carbon-excess conditions by different 50 microorganisms (Pieja et al., 2017). The most common feedstock used for production of 51 PHAs are glucose and fructose, but those carbon sources have a high price, due the market 52 price of PHAs is higher (4-20€ $\mathrm{KgPHA}^{-1}$ ) (Koller et al., 2017). PHAs are currently 53 industrially produced by nearly thirty corporations (Cantera et al., 2019). An innovative 54 feasible alternative to enhance the economic sustainability of the degradation and 
55 valorization of $\mathrm{CH}_{4}$ combined to the concomitant replacement of common plastics is the co56 production of polyhydroxyalkanoates (PHAs) combined with the treatment of methane 57 emissions (Cal et al., 2016; Pieja et al., 2017; Strong et al., 2016). Indeed, several studies 58 have demonstrated that methanotrophs are a potential source of bioplastics, achieving PHA 59 contents ranging from 20 to $60 \%$ (wt) using methane as feedstock (Cantera et al., 2019; 60 Pieja et al., 2017). Methanotrophs are divided into two different groups according to the 61 pathway for carbon assimilation a) type I ( $\gamma$-proteobacteria) use the ribulose 62 monophosphate (RuMP) pathway or b) type II ( $\alpha$ - proteobacteria) use of the serine 63 pathway. Most of the studies reporting PHAs production using methanotrophic bacteria 64 have been conducted with $\alpha$-proteobacterial methanotrophs, since PHAs synthesis supposed 65 to be linked with the serine cycle. Thus, acetyl-CoA molecules produced in the serine cycle 66 are transformed into PHAs via reactions catalyzed by the enzymes $\beta$-ketothiolase 67 (phaA), acetoacetyl-CoA reductase (phaB), and PHAs synthase (phaC) (Cantera et al., 68 2019). Overall, type II methanotrophic bacteria such as Methylocystis, Methylosinus and 69 Methylocella have been considered the main methanotrophic PHA producing genera under 70 nutrient-limited conditions (i.e N-, P- or Mg-limitation) (García-Pérez et al., 2018; Helm et 71 al., 2008; Myung et al., 2017; Rostkowski et al., 2013; Sundstrom and Criddle, 2015; 72 Wendlandt et al., 2001; Zhang et al., 2017).

73 However, the cost-effective implementation of current biotechnologies for the 74 biotransformation of $\mathrm{CH}_{4}$ into bioplastics is still limited by the limited understanding of 75 those factors that determine the selective enrichment of high-performance PHA producing 76 methanotrophs. In this sense, different operational parameters such as $\mathrm{pH}, \mathrm{CH}_{4} / \mathrm{O}_{2}$ ratio, or 77 the concentration of sodium, copper or citrate have been reported as key strategies for the 
enrichment of type II methanotrophs with the ability to synthetize PHA (Pieja et al., 2011; Scheutz et al., 2009; Semrau et al., 2013). However, there is still a need for studies assessing the effect of environmental factors during culture enrichment of PHA producing methanotrophs. The use of an optimal temperature and the inoculum source have been reported as key strategies for the enrichment of microorganisms with the ability to synthetize PHAs using waste water and sugars as carbon sources (De Grazia et al., 2017). Thus, those inocula that favor the enrichment of type II methanotrophs, as well as the set temperature during enrichment could enhance this innovative biotechnology based on the transformation of methane into bioplastics. In this sense, Sphagnum mosses, which occur mainly in peat bogs, conifer forests and moist tundra areas, are described as the bryophytes with the highest richness of type II methanotrophs (Kip et al., 2011; Stępniewska and Kuźniar, 2014). Indeed, the extremophile environments that Sphagnum mosses inhabit, combined with the inherent presence of type II methanotrophs in their outer cortex, suggests their potential as a novel source of effective PHA-accumulating microorganisms (Kadouri et al., 2003; Ruiz et al., 2001; Zhao et al., 2007). Similarly, the stress caused on the metabolism of type II methanotrophs by an exposure to high temperatures might mediate an increase in PHA synthesis.

The study presented here aimed at systematically elucidating the influence of temperature $\left(25^{\circ} \mathrm{C}, 30^{\circ} \mathrm{C}, 37^{\circ} \mathrm{C}\right.$ and $\left.45^{\circ} \mathrm{C}\right)$ during culture enrichment on the PHA synthetizing capacity, kinetics and stoichiometric characteristics, and population structure of microbial communities enriched using Sphagnum peat moss and a mixture of Sphagnum and activated sludge as inoculum.

\section{Materials and Methods}

\subsection{Mineral salt medium and inoculum}


The MSM (a modified NMS medium Whittenbury et al., (1970)) was composed of $\left(\mathrm{g} \mathrm{L}^{-1}\right)$ : $2.25 \mathrm{NaNO}_{3}, 0.1 \mathrm{MgSO}_{4} \cdot 7 \mathrm{H}_{2} \mathrm{O}, 0.02 \mathrm{CaCl}_{2} \cdot 2 \mathrm{H}_{2} \mathrm{O}, 0.68 \mathrm{KH}_{2} \mathrm{PO}_{4}, 6.14 \mathrm{Na}_{2} \mathrm{HPO}_{4} \cdot 12 \mathrm{H}_{2} \mathrm{O}$, $1.3 \times 10^{-3} \mathrm{FeSO}_{4} \cdot 7 \mathrm{H}_{2} \mathrm{O}, 3.5 \times 10^{-3} \mathrm{MnCl}_{2} \cdot 4 \mathrm{H}_{2} \mathrm{O}, \quad 1.5 \times 10^{-3} \quad \mathrm{ZnSO}_{4} \cdot 7 \mathrm{H}_{2} \mathrm{O}, 0.04 \times 10^{-3}$ $\mathrm{Na}_{2} \mathrm{MoO}_{4} \cdot 2 \mathrm{H}_{2} \mathrm{O}, \quad 0.04 \times 10^{-3} \mathrm{CuSO}_{4} \cdot 5 \mathrm{H}_{2} \mathrm{O}, \quad 0.32 \times 10^{-3} \mathrm{CoCl}_{2}$, and $0.2 \times 10^{-3} \mathrm{H}_{3} \mathrm{BO}_{3}$. Moreover, vitamins (biotin, nicotinamid, p.aminobenzoic acid and panthotenic acid) were added to stimulate those methanotrophs that have problems to grow. All chemicals needed for MSM preparation were purchased from PANREAC (Barcelona, Spain), while $\mathrm{CH}_{4}(\geq$ 99.5\%) and $\mathrm{O}_{2}(\geq 99.0 \%)$ were obtained from Abelló Linde S.A. (Barcelona, Spain). Poly [(R)-3-hydroxybutyric acid-co-(R)-3-hydroxyvaleric acid] (molar ratio 88/12, $\geq$ 99.99\%) was purchased from Sigma-Aldrich® (St. Louis, MO, USA).

Fresh activated sludge from a denitrification-nitrification wastewater treatment plant (Valladolid, Spain) (López et al., 2018b) and Sphagnum peat moss from Plantas Carnívoras, (Madrid, Spain) were used as inocula for the enrichment of microorganisms able to degrade $\mathrm{CH}_{4}$ and accumulate PHA. The Sphagnum peat moss was diluted 10 times in MSM prior inoculation.

\subsection{Culture enrichment at different temperatures}

A preliminary enrichment was performed batch-wise for 19 days at $25^{\circ} \mathrm{C}$ in $1250 \mathrm{~mL}$ gastight bottles initially containing $190 \mathrm{~mL}$ of MSM and $20 \mathrm{ml}$ of diluted Sphagnum inoculum (from now on referred as S) or $190 \mathrm{~mL}$ of MSM and $20 \mathrm{ml}$ of diluted Sphagnum + activated sludge $(50 \% / 50 \%)$ (from now on referred as $\mathrm{M})$. The initial mass of inoculum in each preenrichment was 50g/L. The bottles were closed with butyl septa and plastic caps, and the headspace was flushed with pure $\mathrm{O}_{2}$ for $15 \mathrm{~min}$ in order to eliminate the previous air atmosphere. $\mathrm{CH}_{4}$ was then supplied at an initial headspace concentration of $195 \pm 7 \mathrm{~g} \mathrm{~m}^{-3}$ 
126 and the bottles were incubated in an orbital shaker MaxQ 4000 fromThermo Scientific, at

$127200 \mathrm{rpm}$. Aliquots of $10 \mathrm{ml}$ of the final enrichments $\mathrm{S}$ and $\mathrm{M}$ at $25^{\circ} \mathrm{C}$ were transferred to $1281250 \mathrm{~mL}$ gas-tight bottles prepared in duplicate as above described. Five enrichment cycles 129 at $25,30,37$ and $45^{\circ} \mathrm{C}$ (each cycle involving a total $\mathrm{CH}_{4}$ consumption and a complete 130 headspace renewal) were carried out under orbital shaking at $200 \mathrm{rpm}$ in duplicate. The 131 temperature range of these experiments was chosen according to the optimum growth 132 temperature of methanotrophic bacteria that are in general mesophile (Hanson and Hanson, 133 1996). No replacement of the MSM was conducted along the cycles, which entailed that the 134 fifth cycle occurred under nitrogen limiting conditions. This procedure was designed to 135 carry out an enrichment process under high biomass concentrations and low $\mathrm{CH}_{4}$ aqueous 136 concentrations (30 times lower than in the headspace according to the Henry's law constant 137 for $\mathrm{CH}_{4}$ of 30 at $25^{\circ} \mathrm{C}$ (Sander, 2014)) in order to favor the growth of methanotrophs with 138 low apparent $K_{m}$ values. In addition, a second enrichment in fresh MSM inoculated with 20 $139 \mathrm{ml}$ of the final cultivation broth resulting from the $5^{\text {th }}$-cycle enrichment was conducted in 140 duplicate at the different temperatures tested. The concentrations of $\mathrm{CH}_{4}, \mathrm{O}_{2}$ and $\mathrm{CO}_{2}$ in the 141 headspace and of TSS in the cultivation broth were periodically monitored in all 142 enrichment experiments.

\subsection{Influence of the temperature on $\mathrm{CH}_{4}$ biodegradation kinetics}

145 The kinetics study was performed in duplicate, batch-wise in gas-tight bottles (1250 mL) 146 initially containing $200 \mathrm{~mL}$ of MSM and $7.3 \mathrm{mg}$ of fresh biomass (obtained in the late 147 exponential growth phase from a further culture inoculated with the final culture resulting 148 from the second enrichments conducted in section 2.2). The serum bottles were 149 hermetically closed, and the headspace was saturated with oxygen by flushing pure $\mathrm{O}_{2}$ for 
15 min. $\mathrm{CH}_{4}$ was added to the headspace with gas tight syringes up to a final concentration

151 of $194 \pm 7 \mathrm{~g} \mathrm{~m}^{-3}$. The serum bottles were then incubated in an orbital shaker at $25^{\circ} \mathrm{C}, 30^{\circ} \mathrm{C}$

152 or $37^{\circ} \mathrm{C}$ and $200 \mathrm{rpm}$ until methane degradation. $\mathrm{CH}_{4}, \mathrm{O}_{2}$ and $\mathrm{CO}_{2}$ concentrations were

153 periodically determined using a GC-TCD. In the case of the cell biomass it was measured

154 as TSS drawing $3 \mathrm{ml}$ from the cultivation broth. The specific growth rate $(\mu)$ was calculated

155 from the slope of the logarithm of the biomass concentration vs. time. The specific $\mathrm{CH}_{4}$

156 biodegradation rates were estimated from the ratio of the specific growth rates and the

157 observed biomass yields in each experiment. The concentration of total nitrogen (TN) in the

158 cultivation broth was also recorded. Neither significant $\mathrm{CH}_{4}$ biodegradation nor biomass 159 growth was recorded at $45^{\circ} \mathrm{C}$.

\subsection{Influence of the temperature on PHAs accumulation under $N$-limiting conditions}

162 The study was performed in duplicate batch-wise in $1250 \mathrm{~mL}$ gas-tight bottles initially 163 containing $200 \mathrm{~mL}$ of $\mathrm{N}$-free MSM and fresh biomass from the kinetics test (previously 164 centrifuged and resuspended in N-free MSM). The bottles were closed with butyl septa and 165 plastic caps, flushed with $\mathrm{O}_{2}$ for 15 min and $\mathrm{CH}_{4}$ was then supplied at an initial headspace 166 concentration of $177 \pm 7 \mathrm{~g} \mathrm{~m}^{-3}$. The bottles were incubated in an orbital shaker) at $25^{\circ} \mathrm{C}$, $16730^{\circ} \mathrm{C}$ or $37^{\circ} \mathrm{C}$ and $200 \mathrm{rpm}$ until complete $\mathrm{CH}_{4}$ depletion. In addition, fresh biomass 168 enriched at $25^{\circ} \mathrm{C}$ was cultivated under nitrogen starvation conditions at 25,30 and $37^{\circ} \mathrm{C}$, 169 respectively, to elucidate the role of temperature during the accumulation phase. In this test 170 series, the headspace concentrations of $\mathrm{CH}_{4}, \mathrm{O}_{2}$ and $\mathrm{CO}_{2}$, biomass concentration (measured 171 as TSS) in the cultivation broth and the PHB content of the biomass were periodically 172 monitored. 
$175 \mathrm{CH}_{4}, \mathrm{O}_{2}$ and $\mathrm{CO}_{2}$ gas concentrations were determined using a Bruker 430 GC-TCD (Palo 176 Alto, USA $)$ endowed with a CP-Molsieve 5A column $(15 \mathrm{~m} \times 0.53 \mu \mathrm{m} \times 15 \mu \mathrm{m})$ and a CP177 PoraBOND Q column $(25 \mathrm{~m} \times 0.53 \mu \mathrm{m} \times 10 \mu \mathrm{m})$. The oven, injector and detector 178 temperatures were $45^{\circ} \mathrm{C}, 150{ }^{\circ} \mathrm{C}$ and $200^{\circ} \mathrm{C}$, respectively. Helium was the gas carrier at a 179 flow rate of $13.7 \mathrm{~mL} \mathrm{~min}^{-1}$. Cell growth was measured as Total Suspended Solids (TSS) 180 according to Standards Methods (American Public Health Association (APHA) et al., 181 2005). TN concentration was determined following sample filtration $(0.45 \mu \mathrm{m})$ in a TOC182 VCSH attached to a TNM-1 module (Shimadzu, Japan). The bacterial PHB content was 183 measured using a GC-MS (GC System 7820A MSD 5977E, Agilent Technologies, Santa 184 Clara, USA) equipped with a DB-wax column $(30 \mathrm{~m} \times 250 \mu \mathrm{m} \times 0.25 \mu \mathrm{m})$ according to 185 (Frutos et al., 2017).

\section{6-DNA extraction, Illumina library preparation and 16S rRNA gene sequencing}

188 Amplicon sequencing was developed targeting the $16 \mathrm{~S} \mathrm{V3}$ and V4 regions (464bp, 189 Escherichia coli based coordinates) with the bacterial primers S-D-Bact-0341-b-S-17 and 190 S-D-Bact-0785-a- A-21, forward and reverse, respectively according to (Klindworth et al., 191 2013). Universal primers were used instead of specific primers for methanotrophic bacteria 192 with the aim of having a broad view of the bacterial population that could be implied in 193 PHA production. Illumina adapter overhang nucleotide sequences were added to the gene194 specific sequences according to (López et al., 2018b). Library construction was carried out 195 using the Nextera XT DNA Sample Preparation Kit (Illumina, San Diego, CA). Libraries

196 were then normalized and pooled prior to sequencing. Non-indexed PhiX library (Illumina, 
197 San Diego, CA) was used as performance control. Samples containing indexed amplicons

198 were loaded onto the MiSeq reagent cartridge for automated cluster generation paired-end 199 sequencing with a 2x300pb paired-end run (MiSeq Reagent kit v3 (MS-102-3001)) 200 according to manufacturer's instructions (Illumina). The amplicon sequencing analysis was 201 carried by the Foundation for the Promotion of Health and Biomedical Research of 202 Valencia Region (FISABIO, Spain).

203

204 2.7-16S rDNA-based taxonomic analysis

205 Only reads with quality value scores $\geq 20$ in more than $99 \%$ of the sequence after 206 demultiplexing and without ambiguous base calls were further analyzed. Quality analyses, 207 paired-end reads junction and chimera search were carried out using the prinseq-lite 208 program (Schmieder and Edwards, 2011), the FLASH program (Magoc and Salzberg, 209 2011) and the USEARCH program (Edgar, 2010). Taxonomic assignments were then 210 conducted using the RDP- Classifier from the Ribosomal Database Project (Cole et al., 211 2009; Wang et al., 2007). Simpson and Shannon indices were determined using the Vegan 212 library version 2.3e1 (Oksanen et al., 2015). The Krona tool was used to represent relative 213 abundances and confidences within the complex hierarchies of metagenomics 214 classifications (Ondov et al., 2011). Nucleotide sequence dataset obtained in this study has 215 been submitted to NCBI Sequence Read Archive with the bioproject accession 216 PRJNA521405 (https://trace.ncbi.nlm.nih.gov/Traces/study/?acc=PRJNA521405\&go=go). 
219 All analyses were performed using biomass obtained from two biological replicas for each condition. The specific growth rates, biomass yields, specific $\mathrm{CH}_{4}$ biodegradation rates,

221 PHAs contents and PHAs produced per unit of $\mathrm{CH}_{4}$ consumed, were compared pairwise 222 using a single cued t-test assuming equal variance. The differences were considered 223 statistically significant for p-values below 0.05 . The symbols “*”, “**” and "***” were 224 used to indicate values below $0.05,0.01$ and 0.001 , respectively, in the figures. In the 225 particular cases where two conditions were not significantly different from each other, their 226 values were grouped and a t-test was performed compared to a third condition. Vegan 227 (Oksanen et al., 2015) and stats packages in R (Sasaki et al., 2005) were used for the 228 statistical analyses of the metagenomics data.

\section{Theoretical Framework}

\subsection{Stoichiometry of PHA production}

232 PHA production using methane as the sole carbon and energy source requires a biomass 233 formation step under nitrogen excess conditions followed by a PHA accumulation step 234 under nitrogen limiting conditions. This two-stage process can be implemented in two 235 separate units (Figure S1). The $\mathrm{CH}_{4}$ and nitrogen required to produce a unit of PHA 236 (disregarding $\mathrm{CH}_{4}$ maintenance consumption, which is small compared to its consumption 237 associated biomass and PHA formation) will depend on the biomass yield on $\mathrm{CH}_{4}\left(Y_{X / C H 4}\right)$, 238 the potential PHA content accumulated per unit of biomass $\left(F_{P H A}=m_{P H A} / X ; X\right.$ being the 239 initial biomass without PHA accumulation), the PHA yield on $\mathrm{CH}_{4}\left(Y_{\mathrm{PHA} / \mathrm{CH} 4}\right)$ and the 240 fraction of nitrogen contained in the biomass before PHA accumulation $\left(F_{N}\right)$. Thus, the 241 production of one unit of PHA requires the previous formation of an amount of biomass $X$ 
242 equal to $1 / F_{P H A}$, which itself requires a $\mathrm{CH}_{4}$ supply equal to $X / Y_{X / C H 4}$ in the first unit (under

243 nitrogen excess). On the other hand, the amount of $\mathrm{CH}_{4}$ to be supplied to the second unit

244 (under nitrogen limiting conditions) could be estimated as $1 / \mathrm{Y}_{\mathrm{PHA} / \mathrm{CH} 4}$. Therefore, the total

245 methane supplies necessary to obtain a mass unit of PHA $\left(m_{\mathrm{CH} 4}\right)$ can be calculated as

$2461 /\left(F_{P H A} Y_{X / C H 4}\right)+1 / Y_{P H A / C H 4}$. Likewise, the nitrogen required per unit of PHA $m_{N}$ is equal to

$247 F_{N} /\left(F_{P H A}\right)$.

248 3.2. Biodegradation kinetics and gas-liquid $\mathrm{CH}_{4}$ transfer

249 Both the biomass formation and PHA accumulation units require the transfer of $\mathrm{CH}_{4}$ (and 250 oxygen) from the gas emission to the methanotrophic cultivation broth. Under steady state 251 operation, the rate of $\mathrm{CH}_{4}$ and $\mathrm{O}_{2}$ mass transfer per unit of reactor volume will be equal to 252 the volumetric rate of microbial consumption of these substrates. The rate of $\mathrm{CH}_{4}$ mass 253 transport per volume of reactor $\left(R_{C H 4}\right)$ can be described by the following equation (Bordel 254 et al., 2008) (Eq. [1]):

$255 \quad R_{\mathrm{CH}_{4}}=\frac{Q_{g}}{V} \beta_{\mathrm{CH}_{4}}\left(C_{g i n}-H_{\mathrm{CH}_{4}} C_{L}\right)$

256 Where $C_{\text {gin }}$ and $H_{C H 4}$ stand for the inlet concentration and Henry's law constant of $\mathrm{CH}_{4}, \mathrm{~V}$ 257 the bioreactor volume, $Q_{g}$ the gas flow rate and $C_{L}$ the $\mathrm{CH}_{4}$ aqueous concentration in the 258 cultivation broth. The parameter $\beta_{\mathrm{CH} 4}$ ranges between 0 and 1 , and depends mainly on the 259 gas-liquid interface area in the reactor as well as the transport properties of the system 260 (Bordel et al., 2008) (Eq. [2]).

$261 \quad \beta_{C_{4}}=1-\exp \left(\frac{-k_{L} a V}{H_{C_{4}} Q_{g}}\right)$

262 Where $k_{L} a$ represents the volumetric mass transfer coefficient of $\mathrm{CH}_{4}$ in the bioreactor. The 263 value of the parameter $\beta_{C H 4}$ is equal to the maximum fraction of $\mathrm{CH}_{4}$ transferrable from the 264 gas emission to the cultivation broth within the reactor. This parameter is independent from 
265 the biological parameters of the microbial community present in the cultivation broth.

266 Therefore, it is desirable to operate with $\beta_{\mathrm{CH} 4}$ values close to 1 . However, low $\beta_{\mathrm{CH} 4}$ values

267 are typically recorded for gas substrates with a low aqueous solubility such as $\mathrm{CH}_{4}$ (e.g the

268 dimensionless Henry constant $H_{C H 4}$ is equal to 33.5 at $30{ }^{\circ} \mathrm{C}$ (Duan et al., 1992)), which

269 would ultimately limit the performance of PHA production based on $\mathrm{CH}_{4}$. In this context,

270 several high mass transfer performance bioreactors such as two-phase partitioning, Taylor

271 flow or internal gas recycling bioreactors have been engineered to overcome these

272 limitations (Bordel et al., 2010; García-Pérez et al., 2018; Hernández et al., 2011).

273 However, the kinetic parameters of the methanotrophic community influence the $\mathrm{CH}_{4}$ mass

274 transport rate since microbial kinetics ultimately determine the steady state liquid

275 concentration $\left(C_{L}\right)$. The specific biomass growth rate of methanotrophs $(\mu)$ can be

276 accurately described using the Monod’s equation (Eq. [3]):

$277 \mu=\mu_{\max } \frac{C_{L}}{C_{L}+K}$

278 Where $\mu_{\max }$ stands for the maximum specific growth rate and $K$ the Monod half-saturation

279 constant. The specific biomass growth rate in the biomass formation unit under steady state 280 is equal to the dilution rate $D$ (= volumetric liquid flow rate supplied to the reactor divided

281 by the reactor volume). Hence, the $\mathrm{CH}_{4}$ aqueous concentration, $C_{L}$, can be determined as a 282 function of the dilution rate (Eq. [4]).

$283 \quad C_{L}=\frac{D K}{\mu^{\max }-D}$

284 The Monod constant $K$ is equal to the concentration at which the cell growth rate is equal to 285 half its maximum value $\left(\mu_{\max }\right)$. The value of $K$ in methanotrophic cultures typically ranges 286 between 2 and $12 \mu \mathrm{M}$. On the other hand, the maximum specific growth rate sets a 287 threshold to the dilution rate of the bioreactor. Thus, the dilution rate should be at least an 
order of magnitude lower than this critical dilution rate in order to cope with increases in

289 the necessary liquid flow to be processed and to avoid biomass wash-out. Based on 290 equation [1], the fraction $\left(F_{C H 4}\right)$ of $\mathrm{CH}_{4}$ in the gas emission transferred to the cultivation 291 broth can be estimated as follows (Eq. [5]):

$292 F_{C H 4}=\beta_{C H 4} \frac{C_{g i n}-H_{C H 4} C_{L}}{C_{g i n}}$

293 In this context, while the parameter $\beta_{\mathrm{CH} 4}$ depends only on the gas-liquid mass transfer 294 capacity of the bioreactor, $C_{L}$ is governed by the liquid dilution rate and the kinetics 295 parameters of the microbial community. Therefore, the fraction $F_{C H 4}$ can be regarded as the 296 product of a transport limited term and a biologically limited fraction. This biologically 297 limited term is close to 1 for the typical kinetics and operating parameters prevailing in $\mathrm{CH}_{4}$ 298 abatement bioreactors, which entails that the impact of the maximum specific biomass 299 growth rate on the overall process performance is small.

300

301 4. Results

302 4.1. Influence of the enrichment temperature on the specific growth rates

303 A decrease in the specific growth rate of the microbial communities was observed when 304 increasing the selected temperature in the enrichments derived from Sphagnum alone at a 305 significant level of $\mathrm{p} \leq 0.05$ (Figure 1). Thus, average specific growth rates of $0.05 \pm 0.001$ $306 \mathrm{~h}^{-1}, 0.04 \pm 0.004 \mathrm{~h}^{-1}$ and $0.02 \pm 0.004 \mathrm{~h}^{-1}$ were observed at 25,30 and $37^{\circ} \mathrm{C}$, respectively, in $\mathrm{S}$ 307 enrichments. However, the specific growth rates of the microbial communities enriched 308 from the mixed inoculum (M) increased from $0.02 \pm 0.002 \mathrm{~h}^{-1}$ at $25^{\circ} \mathrm{C}$ to $0.033 \pm 0.0009 \mathrm{~h}^{-1}$ at $30937^{\circ} \mathrm{C}$. Interestingly, the specific growth rates of the two M biological replicates enriched at 
$31030^{\circ} \mathrm{C}$ differed strongly $\left(0.022\right.$ and $\left.0.042 \mathrm{~h}^{-1}\right)$, resulting in no statistical differences with the

311 M enrichments at 25 and $37^{\circ} \mathrm{C}$.

\section{< Figure 1>}

\subsection{Influence of the enrichment temperature on the specific $\mathrm{CH}_{4}$ degradation rate}

314 No significant difference was observed between the specific $\mathrm{CH}_{4}$ biodegradation rates of 315 the biomass enriched from Sphagnum at 25 and $30{ }^{\circ} \mathrm{C}\left(65.3 \pm 5.1,79.5 \pm 7.9 \mathrm{mg}_{-} \mathrm{CH}_{4} \mathrm{~h}^{-1} \mathrm{~g}-\right.$ 316 biomass $^{-1}$, respectively; error intervals are standard errors with 2 samples) (Figure 2). 317 However, a significantly lower specific $\mathrm{CH}_{4}$ biodegradation rate was observed at $37^{\circ} \mathrm{C}$ 318 (49.7 $\pm 3.7 \mathrm{mg}-\mathrm{CH}_{4} \mathrm{~h}^{-1}$ g-biomass $\left.{ }^{-1}\right)$, which correlated with the lower $\mu$ recorded at this 319 temperature. On the other hand, the biomass enriched from the mixed inoculum (M) 320 exhibited lower specific $\mathrm{CH}_{4}$ biodegradation rates at 25 and $30^{\circ} \mathrm{C}(48.2 \pm 2.5$ and $51.7 \pm 1.9$ $321 \mathrm{mg}_{-} \mathrm{CH}_{4} \mathrm{~h}^{-1}$ g-biomass ${ }^{-1}$, respectively) than at $37^{\circ} \mathrm{C}\left(78.9 \pm 5.6 \mathrm{mg} \mathrm{CH}_{4} \mathrm{~h}^{-1} \mathrm{~g}_{\text {biomass }}{ }^{-1}\right)$. The 322 differences obtained between the specific $\mathrm{CH}_{4}$ biodegradation rates of $\mathrm{S}$ and $\mathrm{M}$ confirmed 323 that the experiments were conducted under non-mass transfer limiting conditions.

$<$ Figure 2>

\subsection{Influence of the enrichment temperature on PHAs content}

327 The content of biopolymers accumulated by the microorganisms of both inocula increased 328 with temperature. Polyhydroxybutyrate was the dominant PHA in all the samples analysed. 329 The biomass enriched at 30 and $37^{\circ} \mathrm{C}$ was able to accumulate over $30 \%$ of PHA inside the 330 cells $\left(35.1 \pm 0.4 \%\right.$ and $33.1 \pm 1.3 \%$ in $\mathrm{S}$ at $30^{\circ} \mathrm{C}$ and $37^{\circ} \mathrm{C}$, respectively, and $28.4 \pm 1.1 \%$ 331 and $34.1 \pm 1.3 \%$ in $\mathrm{M}$ at $30^{\circ} \mathrm{C}$ and $37^{\circ} \mathrm{C}$, respectively) under nitrogen limiting conditions, 332 compared to the PHA contents of $15.7 \pm 2.4 \%$ and $21.2 \pm 2.0 \%$ in $\mathrm{S}$ and $\mathrm{M}$ biomass, 
respectively, at $25^{\circ} \mathrm{C}$ (Figure 3). The mass of $\mathrm{PHA}$ per unit of $\mathrm{CH}_{4}$ consumed was also obtained from experiments conducted under $\mathrm{N}$ limiting conditions. Interestingly, no significant difference was observed among the 6 microbial communities enriched, with average values of $0.22 \pm 0.05 \mathrm{~g}$-PHA $\left(\mathrm{g}^{-} \mathrm{CH}_{4}\right)^{-1}$. In this context, this value has been previously reported to be $0.57 \mathrm{~g}-\mathrm{PHA}\left(\mathrm{g}-\mathrm{CH}_{4}\right)^{-1}$ for pure cultures of Methylocystis hirsuta, which is a high-performance PHA accumulating methanotrophic strain (López et al., 2018a). Similarly, Chidambarampadmavathy et al. (2017), using a consortium enriched from landfill soil and dominated by Methylosarcina sp., obtained maximal PHB contents of $25 \mathrm{mg}$ g biomass-1 at $40 \%$ of $\mathrm{CH}_{4}$ in air. Zhang et al., 2018 reported accumulations of $\sim 45 \%$ of $\mathrm{PHB}$ in a mixed culture enriched from sewage sludge under $\mathrm{N}$ limitation and with $\mathrm{Cu}$, whereas the absence of $\mathrm{Cu}$ diminished PHB synthesis (12\%-18\%).”

\section{<Figure 3>}

4.4 Influence of the enrichment temperature on biomass yield

The biomass enriched from Sphagnum at $25^{\circ} \mathrm{C}$ showed a yield on $\mathrm{CH}_{4}$ almost twice as high as the biomass enriched from this inoculum source at the two other temperatures (Figure 4). This higher yield was also correlated to the higher specific growth rate observed at this temperature. As discussed later, this higher yield might be somehow related to the higher population diversity observed in this sample. The biomass derived from the mixed inoculum at $25^{\circ} \mathrm{C}$ did not show yields higher than that enriched at 30 and $37^{\circ} \mathrm{C}$. In contrast, the higher yield on $\mathrm{CH}_{4}$ was recorded in the biomass enriched at $30^{\circ} \mathrm{C}$. 
357 From an industrial perspective, this study aimed at elucidating the optimal enrichment 358 temperature and inoculum source that potentially result in the most effective usage of raw 359 materials (in this case $\mathrm{CH}_{4}$ and $\mathrm{N}$ ). Table 1 depicts the $\mathrm{CH}_{4}$ and nitrogen required to 360 produce a unit of PHA as a function of the enrichment temperature and inoculum source.

361 The most cost-effective biomass for optimal PHA production would be the enrichment 362 from Sphagnum at $30^{\circ} \mathrm{C}$. This biomass required the lowest $\mathrm{CH}_{4}$ input $(10.5 \pm 1.4 \mathrm{~g} \mathrm{CH} \mathrm{g}$ $363 \mathrm{PHA}^{-1}$; equal to that required by the biomass obtained at $30^{\circ} \mathrm{C}$ from the mixed inoculum) 364 and also the lowest nitrogen input $\left(0.2 \mathrm{~g} \mathrm{~N} \mathrm{~g} \mathrm{PHA}^{-1}\right)$.

$\langle$ Table 1>

\subsection{Influence of the temperature during the accumulation phase on PHA content}

368 The results herein obtained showed that, independently of the inoculum source, the biomass 369 enriched at 30 and $37^{\circ} \mathrm{C}$ led to the highest PHA yields. In the previous experiments in 370 literature, biomass enrichment and PHA synthesis (under nitrogen limitation) were carried 371 out at a constant temperature (García-Pérez et al., 2018; López et al., 2018a, 2018b; Myung 372 et al., 2017; Zhang et al., 2017). In order to elucidate whether these higher PHA yields were 373 the result of the temperature during the enrichment or accumulation phase, the biomass 374 enriched at $25^{\circ} \mathrm{C}$ was supplied with $\mathrm{CH}_{4}$ under nitrogen starvation conditions at 25, 30 and $37537^{\circ} \mathrm{C}$. No increase in the PHA content of the biomass enriched at $25^{\circ} \mathrm{C}$ was observed at the 376 two highest temperatures. Indeed, a slight decrease (no statistically significant) was found 377 at 30 and $37^{\circ} \mathrm{C}$ (Figure 5). 
381 The enrichment process (pre-enrichment +5 growth stages till complete $\mathrm{N}$ depletion +2 382 growth stages +1 PHA accumulation stage) resulted in the dominance of the genus 383 Methylocystis (with percentages close to 30\%, Figure S2) in the enriched communities 384 regardless of the inoculum source and temperatures. Members of this genus, which was 385 almost absent in the initial inocula, are capable of synthetizing PHA under nitrogen 386 deprivation conditions (López et al., 2018a). The biomass enriched from Sphagnum 387 contained a low number of other methanotrophs and methylotrophs $(\sim 1 \%$ of 388 Methylobacterium at 30 and $37^{\circ} \mathrm{C}$, and $2 \%$ of Methylophylus at $25^{\circ} \mathrm{C}$ ). On the other hand, 389 the biomass enriched from the mixed Sphagnum and activated sludge inoculum contained 390 significant amounts of methylotrophs such as Methylophilus (17\% of the community 391 enriched at $\left.25^{\circ} \mathrm{C}\right)$, Methylobacterium (5\% of the community enriched at $30^{\circ} \mathrm{C}$ ) and 392 methanotrophs such as Methyloparacocus ( $9 \%$ of the community enriched at $\left.30^{\circ} \mathrm{C}\right)$. These 393 methanotrophs and methylotrophs different from the genus Methylocystis were less 394 abundant in the community enriched at $37^{\circ} \mathrm{C}(1 \%$ of Methylobacterium). The results here 395 obtained revealed that temperature was a strong selective pressure for the enrichment of 396 PHA accumulating bacteria regardless of the inoculum.

397 None of the characteristics of the microbial communities enriched (specific growth rate, 398 PHA accumulation etc.) seemed to be explained by changes in the overall microbial 399 composition. For example, the enrichments conducted at 30 and $37^{\circ} \mathrm{C}$, which resulted in 400 higher PHA accumulations, did not contain a higher percentage of Methylocystis than those 401 conducted at $25^{\circ} \mathrm{C}$.

402 5. Discussion 
404 This study aimed at assessing both the feasibility of enriching PHA accumulating methanotrophic consortia from Sphagnum mosses-based inocula (based on their high inherent abundance in type II methanotrophs) and the influence of the temperature on the characteristics of the communities enriched. The prolonged exposure of the inocula to methane as the only carbon and energy source (following the described enrichment protocol) allowed to enrich microbial consortia where the genus Methylocystis was the most abundant (which represented approx. 30\% of the total microbial population) regardless of the enrichment temperature. Methylocystis are known to accumulate PHA, however no selective pressure aiming to favour PHA accumulating organisms (such as alternate cycles of nitrogen starvation) was specifically imposed during the enrichment process. The specific growth rates of the consortia enriched were up to two folds higher than those previously reported for pure cultures of Methylocystis hirsuta (López et al., 2018a) (0.021 $\mathrm{h}^{-1}$ ), likely due to the symbiotic effects with other microbial populations. In this context, the purer a culture is, the higher are the restrictions to grow under environmental stress factors, while a higher population richness and diversity promotes higher resilience and therefore, better bio-product recovery (Cabrol et al., 2012). Moreover, adaptive laboratory evolution could be also carried out to gain insights into the adaptive changes that experience microbial populations during long-term selection: better PHA productivity and higher methane degradation rates (Dragosits and Mattanovich, 2013).

\subsection{Specific growth rate and microbial $\mathrm{CH}_{4}$ bioconversion}

In addition, the theoretical framework developed in section 3 reveals that a microbial community with a maximum specific growth rate of $0.02 \mathrm{~h}^{-1}$ (the minimum recorded in this 
427

428

429

430

431

432

433

434

435

436

437

438

439

440

441

442

443

444

445

446 Since temperature has been determined as an important factor that modifies PHA

447 accumulation in other heterotrophic bacteria (Myshkina et al., 2008), this study aimed to

448

449

study) treating a gas emissions with typical $\mathrm{CH}_{4}$ inlet concentration of $6 \%$ (equivalent to an equilibrium concentration of $0.0024 \mathrm{M}$ in the aqueous phase) will eventually support a $\mathrm{CH}_{4}$ removal of $99.2 \%$ in the bioreactor (under no mass transfer limitations), while a biomass with a maximum specific growth rate of $0.05 \mathrm{~h}^{-1}$ (the maximum recorded in this study) will support a potential $\mathrm{CH}_{4}$ removal of $99.7 \%$. These estimations clearly show that the maximum specific growth rate of the microbial community enriched does not represent a key parameter in suspended-growth $\mathrm{CH}_{4}$ bioconversion processes operated under continuous mode. The scenario would be different if the process was performed batch-wise, where higher maximum specific growth rates would result in shorter production times.

The biomass yields on methane here recorded were of the same order as those of pure cultures of Methylocystis, with the exception of the consortium enriched from the inoculum $\mathrm{S}$ at $25^{\circ} \mathrm{C}$, which showed a biomass yield almost twice as large as that of a pure Methylocystis hirsuta cultures. It can be hypothesized that this unusually high yield $\left(\mathrm{YX} / \mathrm{CH}_{4}=0.8\right)$ was supported by the high microbial diversity of this particular enrichment $(\mathrm{H}=2.84)$. A weak correlation between the biomass yield and the microbial diversity was also observed $(\mathrm{R}=0.764$ and a $\mathrm{p}$-value $=0.109)$, which has been previously described in literature (Louis et al., 2016).

\subsection{Effect of temperature on the enrichment conditions and on PHA accumulation} assess the optimal temperature conditions to increase the production of PHA using type II methanotrophs. Culture enrichment at 30 and $37^{\circ} \mathrm{C}$ resulted in consortia able to accumulate 
significantly higher amounts of PHA under nitrogen starvation (30\% of the total microbial

451 biomass) than those enriched at $25^{\circ} \mathrm{C}$. These values were low in comparison to the PHA 452 contents of 40-47\% (wt) reported by Zhang et al. 2018. This result was probably due to the 453 high copper concentration used for enrichment by Zhang et al. 2018 which increased PHA 454 accumulation by a factor of 2.5. Concentrations of copper characteristic of urban waste 455 water treatment plants were used in this study to avoid the effect of additional variables on 456 the results obtained not related to temperature (Zhang et., 2018). Nevertheless, the fact that 457 only $30 \%$ of the DNA of the enriched consortia corresponded to bacteria of the genus 458 Methylocystis (the only described PHA accumulating organism identified in these 459 consortia) suggested that the strains of this genus in these specific enrichments could 460 eventually contain up to $70 \%$ of PHA. In this regard, under nutrient-limited conditions 461 Methylocystis, Methylosinus and Methylocella, which are considered the main 462 methanotrophic PHA producers to date, are able to achieve PHA accumulations ranging 463 from 20 to 50\% (wt) (García-Pérez et al., 2018; Pieja et al., 2012; Zhang et al., 2017) 464 values that are lower than the ones suggest by previous research.

465 The fact that the results obtained for the PHA content of the microbial communities 466 enriched at different temperatures were just due to the temperature prevailing during the 467 accumulation phase was discarded by performing PHA accumulation experiments at 25, 30 468 and $37^{\circ} \mathrm{C}$ with biomass enriched from Sphagnum at $25^{\circ} \mathrm{C}$. No enhancement in PHA 469 accumulation was observed at 30 and $37^{\circ} \mathrm{C}$, which confirmed that culture enrichment at 470 higher temperatures plays a key role on the selection of more efficient PHA accumulators. 471 However, the mechanisms underlying the superior accumulation of PHA in communities 472 enriched at higher temperatures remains unknown. In this context, it has been speculated 473 that temperature acts as an environmental stress analogous to nitrogen depletion and 
474 triggers PHA accumulation. However, only trace levels of PHA were observed at 30 or $47537^{\circ} \mathrm{C}$ in cultures grown under nitrogen sufficient conditions and there was not a direct 476 influence of temperature on PHA accumulation under nitrogen limiting conditions during 477 the accumulation phase. At this point it can be speculated that some molecular mechanisms 478 involved in heat shock resistance might also enable methanotrophs to accumulate higher 479 PHA contents. Finally, it should be highlighted that lower temperatures increase $\mathrm{CH}_{4} \mathrm{mass}$ 480 transfer from the gas to the microbial community as a result of a decrease in the Henry's 481 law constant, which directly impact on the gas-liquid concentration gradient and could 482 influence the specific growth rates and PHA content of the biomass. However, the 483 theoretically enhanced $\mathrm{CH}_{4}$ mass transfer at lower temperatures did not increase the PHA 484 content of the microbial communities enriched.

\section{Conclusions}

487 This study confirmed the key role that the enrichment temperature plays on microbial PHA 488 production from $\mathrm{CH}_{4}$, culture enrichment at high temperatures $\left(30\right.$ and $37^{\circ} \mathrm{C}$ ) resulted in a 489 superior PHA accumulation compared to the biomass enriched at $25^{\circ} \mathrm{C}$. This finding 490 suggests that temperature has an important in PHA accumulation and could enhance the 491 implementation of PHA cell factories.

\section{Acknowledgements}

494 This research was funded by the Spanish Ministry of Economy and Competitiveness, the 495 European FEDER program and the European Commission (CTM2015-73228-JIN, H2020496 MSCA-IF-2016: CH4BioVal-GA:750126 and Red NOVEDAR). The financial support from 
497

498

499

500

501

502

503

504

505

506

507

508

509

510

511

512

513

514

515

516

517

518

519

520

521

522

523

524

525

526

the regional government of Castilla y León is also gratefully acknowledged (UIC71).

Declarations of interest: none.

\section{References}

(EPA), E.P.A., 2017. Green Enterprise - Environmental Protection Agency (EPA. Environ. Prot. Agency.

American Public Health Association (APHA), American Water Works Association, Water Environment Federation, 2005. Standard Methods for the Examination of Water and Wastewater 21st Edition, Standard Methods.

Bordel, S., Hernandez, M., Villaverde, S., Muñoz, R., 2010. Modelling gas-liquid VOCs transport in two-liquid phase partitioning bioreactors. Int. J. Heat Mass Transf. 53, 1139-1145. https://doi.org/10.1016/j.ijheatmasstransfer.2009.10.042

Bordel, S., Muñoz, R., Díaz, L.F., Villaverde, S., 2008. Mechanistic model for evaluating the performance of suspended growth bioreactors for the off-gas treatment of VOCs. Biochem. Eng. J. 38, 395-405. https://doi.org/10.1016/j.bej.2007.08.004

Cabrol, L., Malhautier, L., Poly, F., Roux, X. Le, Lepeuple, A.-S., Fanlo, J.-L., 2012. Resistance and resilience of removal efficiency and bacterial community structure of gas biofilters exposed to repeated shock loads. Bioresour. Technol. 123, 548-557. https://doi.org/10.1016/j.biortech.2012.07.033

Cal, A.J., Sikkema, W.D., Ponce, M.I., Franqui-Villanueva, D., Riiff, T.J., Orts, W.J., Pieja, A.J., Lee, C.C., 2016. Methanotrophic production of polyhydroxybutyrate-cohydroxyvalerate with high hydroxyvalerate content. Int. J. Biol. Macromol. 87, 302307. https://doi.org/10.1016/j.ijbiomac.2016.02.056

Cantera, S., Bordel, S., Lebrero, R., Gancedo, J., García-Encina, P.A., Muñoz, R., 2019. Bio-conversion of methane into high profit margin compounds: an innovative, environmentally friendly and cost-effective platform for methane abatement. World $\mathrm{J}$. Microbiol. Biotechnol. 35, 16. https://doi.org/10.1007/s11274-018-2587-4

Chidambarampadmavathy, K., Karthikeyan, O.P., Huerlimann, R., Maes, G.E., Heimann, K., 2017. Response of mixed methanotrophic consortia to different methane to oxygen ratios. Waste Manag. 61, 220-228. https://doi.org/10.1016/j.wasman.2016.11.007 
Cole, J.R., Wang, Q., Cardenas, E., Fish, J., Chai, B., Farris, R.J., Kulam-Syed-Mohideen, A.S., McGarrell, D.M., Marsh, T., Garrity, G.M., Tiedje, J.M., 2009. The Ribosomal Database Project: improved alignments and new tools for rRNA analysis. Nucleic Acids Res. 37, D141-D145. https://doi.org/10.1093/nar/gkn879

De Grazia, G., Quadri, L., Majone, M., Morgan-Sagastume, F., Werker, A., 2017. Influence of temperature on mixed microbial culture polyhydroxyalkanoate production while treating a starch industry wastewater. J. Environ. Chem. Eng. 5, 5067-5075. https://doi.org/10.1016/j.jece.2017.09.041

Desai, M., Harvey, R.P., 2010. Executive summary. New Dir. Youth Dev. 2010, 5-11. https://doi.org/10.1002/yd.370

Dragosits, M., Mattanovich, D., 2013. Adaptive laboratory evolution - principles and applications for biotechnology. Microb. Cell Fact. 12, 64. https://doi.org/10.1186/1475-2859-12-64

Duan, Z., Møller, N., Greenberg, J., Weare, J.H., 1992. The prediction of methane solubility in natural waters to high ionic strength from 0 to $250^{\circ} \mathrm{C}$ and from 0 to 1600 bar. Geochim. Cosmochim. Acta 56, 1451-1460. https://doi.org/10.1016/00167037(92)90215-5

Edgar, R.C., 2010. Search and clustering orders of magnitude faster than BLAST. Bioinformatics 26, 2460-2461. https://doi.org/10.1093/bioinformatics/btq461

Frutos, O.D., Cortes, I., Cantera, S., Arnaiz, E., Lebrero, R., Muñoz, R., 2017. Nitrous Oxide Abatement Coupled with Biopolymer Production As a Model GHG Biorefinery for Cost-Effective Climate Change Mitigation. Environ. Sci. Technol. 51, 6319-6325. https://doi.org/10.1021/acs.est.7b00643

García-Pérez, T., López, J.C., Passos, F., Lebrero, R., Revah, S., Muñoz, R., 2018. Simultaneous methane abatement and PHB production by Methylocystis hirsuta in a novel gas-recycling bubble column bioreactor. Chem. Eng. J. 334, 691-697. https://doi.org/10.1016/j.cej.2017.10.106

Hanson, R.S., Hanson, T.E., 1996. Methanotrophic bacteria. Microbiol. Rev. 60, 439-71. Helm, J., Wendlandt, K.-D., Jechorek, M., Stottmeister, U., 2008. Potassium deficiency results in accumulation of ultra-high molecular weight poly- $\beta$-hydroxybutyrate in a methane-utilizing mixed culture. J. Appl. Microbiol. 105, 1054-1061. 
https://doi.org/10.1111/j.1365-2672.2008.03831.x

Hernández, M., Quijano, G., Muñoz, R., Bordel, S., 2011. Modeling of VOC mass transfer in two-liquid phase stirred tank, biotrickling filter and airlift reactors. Chem. Eng. J. 172, 961-969. https://doi.org/10.1016/j.cej.2011.07.008

Kadouri, D., Jurkevitch, E., Okon, Y., 2003. Involvement of the Reserve Material Poly- Hydroxybutyrate in Azospirillum brasilense Stress Endurance and Root Colonization. Appl. Environ. Microbiol. 69, 3244-3250. https://doi.org/10.1128/AEM.69.6.32443250.2003

Kip, N., Dutilh, B.E., Pan, Y., Bodrossy, L., Neveling, K., Kwint, M.P., Jetten, M.S.M., Op den Camp, H.J.M., 2011. Ultra-deep pyrosequencing of pmoA amplicons confirms the prevalence of Methylomonas and Methylocystis in Sphagnum mosses from a Dutch peat bog. Environ. Microbiol. Rep. 3, 667-673. https://doi.org/10.1111/j.17582229.2011.00260.x

Klindworth, A., Pruesse, E., Schweer, T., Peplies, J., Quast, C., Horn, M., Glöckner, F.O., 2013. Evaluation of general 16S ribosomal RNA gene PCR primers for classical and next-generation sequencing-based diversity studies. Nucleic Acids Res. 41, e1-e1. https://doi.org/10.1093/nar/gks808

Koller, M., Maršálek, L., de Sousa Dias, M.M., Braunegg, G., 2017. Producing microbial polyhydroxyalkanoate (PHA) biopolyesters in a sustainable manner. N. Biotechnol. 37, 24-38. https://doi.org/10.1016/j.nbt.2016.05.001

Löhr, A., Savelli, H., Beunen, R., Kalz, M., Ragas, A., Van Belleghem, F., 2017. Solutions for global marine litter pollution. Curr. Opin. Environ. Sustain. 28, 90-99. https://doi.org/10.1016/j.cosust.2017.08.009

López, J.C., Arnáiz, E., Merchán, L., Lebrero, R., Muñoz, R., 2018a. Biogas-based polyhydroxyalkanoates production by Methylocystis hirsuta: A step further in anaerobic digestion biorefineries. Chem. Eng. J. 333, 529-536. https://doi.org/10.1016/j.cej.2017.09.185

López, J.C., Merchán, L., Lebrero, R., Muñoz, R., 2018b. Feast-famine biofilter operation for methane mitigation. J. Clean. Prod. 170, 108-118. https://doi.org/10.1016/j.jclepro.2017.09.157

Louis, B.P., Maron, P.-A., Menasseri-Aubry, S., Sarr, A., Lévêque, J., Mathieu, O., Jolivet, 
C., Leterme, P., Viaud, V., 2016. Microbial Diversity Indexes Can Explain Soil Carbon Dynamics as a Function of Carbon Source. PLoS One 11, e0161251. https://doi.org/10.1371/journal.pone.0161251

Magoc, T., Salzberg, S.L., 2011. FLASH: fast length adjustment of short reads to improve genome assemblies. Bioinformatics 27, 2957-2963. https://doi.org/10.1093/bioinformatics/btr507

Myshkina, V.L., Nikolaeva, D.A., Makhina, T.K., Bonartsev, A.P., Bonartseva, G.A., 2008. Effect of growth conditions on the molecular weight of poly-3-hydroxybutyrate produced by Azotobacter chroococcum 7B. Appl. Biochem. Microbiol. 44, 482-486. https://doi.org/10.1134/S0003683808050050

Myung, J., Flanagan, J.C.A., Waymouth, R.M., Criddle, C.S., 2017. Expanding the range of polyhydroxyalkanoates synthesized by methanotrophic bacteria through the utilization of omega-hydroxyalkanoate co-substrates. AMB Express 7, 118. https://doi.org/10.1186/s13568-017-0417-y

Oksanen, J., Blanchet, F.G., Kindt, R., Legendre, P., Minchin, P.R., O’Hara, R.B., Simpson, G.L., Solymos, P., Stevens, M.H.H., Wagner, H., 2015. vegan: Community Ecology Package. R package version 2.3-1. http://CRAN.Rproject.org/package=vegan.

Ondov, B.D., Bergman, N.H., Phillippy, A.M., 2011. Interactive metagenomic visualization in a Web browser. BMC Bioinformatics 12, 385. https://doi.org/10.1186/1471-210512-385

Pieja, A.J., Morse, M.C., Cal, A.J., 2017. Methane to bioproducts: the future of the bioeconomy? Curr. Opin. Chem. Biol. 41, 123-131. https://doi.org/10.1016/j.cbpa.2017.10.024

Pieja, A.J., Sundstrom, E.R., Criddle, C.S., 2012. Cyclic, alternating methane and nitrogen limitation increases PHB production in a methanotrophic community. Bioresour. Technol. 107, 385-392. https://doi.org/10.1016/j.biortech.2011.12.044

Pieja, A.J., Sundstrom, E.R., Criddle, C.S., 2011. Poly-3-Hydroxybutyrate Metabolism in the Type II Methanotroph Methylocystis parvus OBBP. Appl. Environ. Microbiol. 77, 6012-6019. https://doi.org/10.1128/AEM.00509-11

Rostkowski, K.H., Pfluger, A.R., Criddle, C.S., 2013. Stoichiometry and kinetics of the 
PHB-producing Type II methanotrophs Methylosinus trichosporium OB3b and Methylocystis parvus OBBP. Bioresour. Technol. 132, 71-77. https://doi.org/10.1016/j.biortech.2012.12.129

Ruiz, J.A., Lopez, N.I., Fernandez, R.O., Mendez, B.S., 2001. Polyhydroxyalkanoate Degradation Is Associated with Nucleotide Accumulation and Enhances Stress Resistance and Survival of Pseudomonas oleovorans in Natural Water Microcosms. Appl. Environ. Microbiol. 67, 225-230. https://doi.org/10.1128/AEM.67.1.225230.2001

Sander, R., 2014. Compilation of Henry's law constants, version 3.99. Atmos. Chem. Phys. Discuss. 14, 29615-30521. https://doi.org/10.5194/acpd-14-29615-2014

Sasaki, T., Massaki, N., Kubo, T., 2005. Wolbachia variant that induces two distinct reproductive phenotypes in different hosts. Heredity (Edinb). 95, 389-393. https://doi.org/10.1038/sj.hdy.6800737

Scheutz, C., Kjeldsen, P., Bogner, J.E., De Visscher, A., Gebert, J., Hilger, H.A., HuberHumer, M., Spokas, K., 2009. Microbial methane oxidation processes and technologies for mitigation of landfill gas emissions. Waste Manag. Res. 27, 409-455. https://doi.org/10.1177/0734242X09339325

Schmieder, R., Edwards, R., 2011. Quality control and preprocessing of metagenomic datasets. Bioinformatics 27, 863-864. https://doi.org/10.1093/bioinformatics/btr026

Semrau, J.D., Jagadevan, S., DiSpirito, A.A., Khalifa, A., Scanlan, J., Bergman, B.H., Freemeier, B.C., Baral, B.S., Bandow, N.L., Vorobev, A., Haft, D.H., Vuilleumier, S., Murrell, J.C., 2013. Methanobactin and MmoD work in concert to act as the 'copperswitch' in methanotrophs. Environ. Microbiol. 15(11), 3077-3086. https://doi.org/10.1111/1462-2920.12150

Sigler, M., 2014. The Effects of Plastic Pollution on Aquatic Wildlife: Current Situations and Future Solutions. Water, Air, Soil Pollut. 225, 2184. https://doi.org/10.1007/s11270-014-2184-6

Stępniewska, Z., Kuźniar, A., 2014. Cultivation and detection of endophytic aerobic methanotrophs isolated from Sphagnum species as a perspective for environmental biotechnology. AMB Express 4, 58. https://doi.org/10.1186/s13568-014-0058-3

Strong, P.J., Kalyuzhnaya, M., Silverman, J., Clarke, W.P., 2016. A methanotroph-based 
651

652

653

654

655

656

657

658

659

660

661

662

663

664

665

666

667

668

669

670

671

672

673

674

675

676

677

678

679

680

681 biorefinery: Potential scenarios for generating multiple products from a single fermentation. Bioresour. Technol. 215, 314-323.

https://doi.org/10.1016/j.biortech.2016.04.099

Sundstrom, E.R., Criddle, C.S., 2015. Optimization of Methanotrophic Growth and Production of Poly(3-Hydroxybutyrate) in a High-Throughput Microbioreactor System. Appl. Environ. Microbiol. 81, 4767-4773.

https://doi.org/10.1128/AEM.00025-15

Wang, Q., Garrity, G.M., Tiedje, J.M., Cole, J.R., 2007. Naive Bayesian Classifier for Rapid Assignment of rRNA Sequences into the New Bacterial Taxonomy. Appl. Environ. Microbiol. 73, 5261-5267. https://doi.org/10.1128/AEM.00062-07

Wendlandt, K.-D., Jechorek, M., Helm, J., Stottmeister, U., 2001. Producing poly-3hydroxybutyrate with a high molecular mass from methane. J. Biotechnol. 86, 127133. https://doi.org/10.1016/S0168-1656(00)00408-9

Whittenbury, R., Phillips, K.C., Wilkinson, J.F., 1970. Enrichment, Isolation and Some Properties of Methane-utilizing Bacteria. J. Gen. Microbiol. 61, 205-218. https://doi.org/10.1099/00221287-61-2-205

Zhang, T., Wang, X., Zhou, J., Zhang, Y., 2018. Enrichments of methanotrophicheterotrophic cultures with high poly- $\beta$-hydroxybutyrate (PHB) accumulation capacities. J. Environ. Sci. 65, 133-143. https://doi.org/10.1016/j.jes.2017.03.016

Zhang, T., Zhou, J., Wang, X., Zhang, Y., 2017. Coupled effects of methane monooxygenase and nitrogen source on growth and poly- $\beta$-hydroxybutyrate (PHB) production of Methylosinus trichosporium OB3b. J. Environ. Sci. 52, 49-57. https://doi.org/10.1016/j.jes.2016.03.001

Zhao, Y.H., Li, H.M., Qin, L.F., Wang, H.H., Chen, G.-Q., 2007. Disruption of the polyhydroxyalkanoate synthase gene in Aeromonas hydrophila reduces its survival ability under stress conditions. FEMS Microbiol. Lett. 276, 34-41. https://doi.org/10.1111/j.1574-6968.2007.00904.x 
Table 1. Methane and nitrogen requirements and biomass production per gram of PHA produced.

\begin{tabular}{|c|c|c|c|c|c|c|}
\hline & \multicolumn{3}{|c|}{ Sphagnum } & \multicolumn{2}{|c|}{$\begin{array}{l}\text { Sphagnum } \\
\text { sludge }\end{array}$} & \multirow{2}{*}{$\begin{array}{c}\text { Activated } \\
37^{\circ} \mathrm{C}\end{array}$} \\
\hline & $25^{\circ} \mathrm{C}$ & $30^{\circ} \mathrm{C}$ & $37^{\circ} \mathrm{C}$ & $25^{\circ} \mathrm{C}$ & $30^{\circ} \mathrm{C}$ & \\
\hline Biomass per gram of PHA (g) & $6.3 \pm 0.6$ & $2.8 \pm 0.04$ & $3 \pm 0.05$ & $4.7 \pm 0.2$ & $3.5 \pm 0.2$ & $2.9 \pm 0.1$ \\
\hline $\mathrm{CH}_{4}$ growth phase (g) & $4.5 \pm 1$ & $4.5 \pm 1$ & $4.5 \pm 1$ & $4.5 \pm 1$ & $4.5 \pm 1$ & $4.5 \pm 1$ \\
\hline $\mathrm{CH}_{4}$ accumulation phase (g) & $7.9 \pm 2.4$ & $6 \pm 0.4$ & $7 \pm 1.3$ & $10.5 \pm 2$ & $5.8 \pm 1$ & $6.8 \pm 1.4$ \\
\hline Total $\mathrm{CH}_{4}$ per gram of PHA (g) & $12.5 \pm 3.4$ & $10.5 \pm 1.4$ & $11.6 \pm 2.3$ & $15 \pm 3$ & $10.3 \pm 2$ & $11.4 \pm 2.4$ \\
\hline Nitrogen per gram of PHA (g) & $0.5 \pm 0.1$ & $0.2 \pm 0.0$ & $0.2 \pm 0.0$ & $0.3 \pm 0.0$ & $0.3 \pm 0.0$ & $0.2 \pm 0.0$ \\
\hline
\end{tabular}


704

705

706

707

708

709

710

711

712

713

714

715

716

717

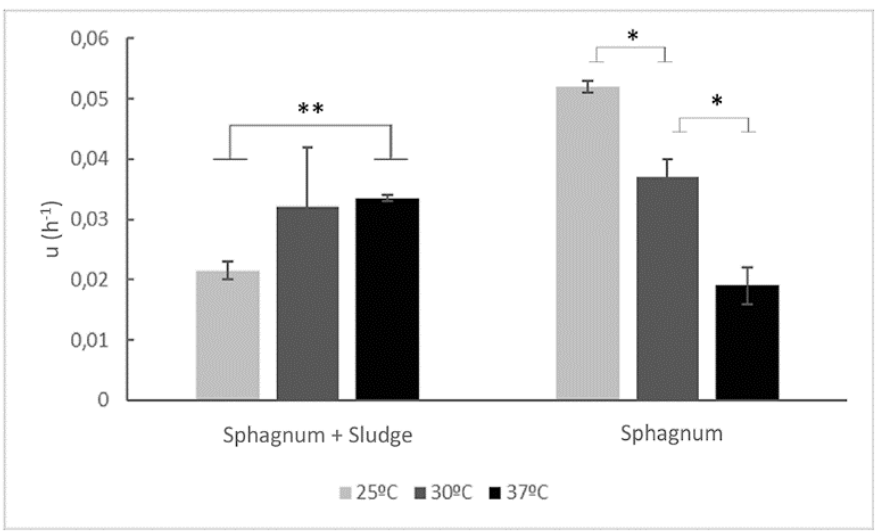

718 Figure 1. Influence of the enrichment temperature on the specific growth rates for the

719 communities enriched from Sphagnum and Sphagnum + activated sludge. For the mixed

720 Sphagnum and activated sludge inoculum, error bars show standard errors $(\mathrm{n}=2)$, and the

721 specific growth rate of the biomass enriched at $37{ }^{\circ} \mathrm{C}$ was significantly higher than the 
722 growth rate at $25{ }^{\circ} \mathrm{C}(\mathrm{p}$-value $0.008, \mathrm{n}=2)$. For Sphagnum inoculum, the opposite trend was 723 observed, with decreasing specific growth rates at higher temperatures (p-values of 0.02 724 between 25 and $30^{\circ} \mathrm{C}$ and 0.03 between 30 and $\left.37^{\circ} \mathrm{C}, \mathrm{n}=2\right)$.

725

726

727

728

729

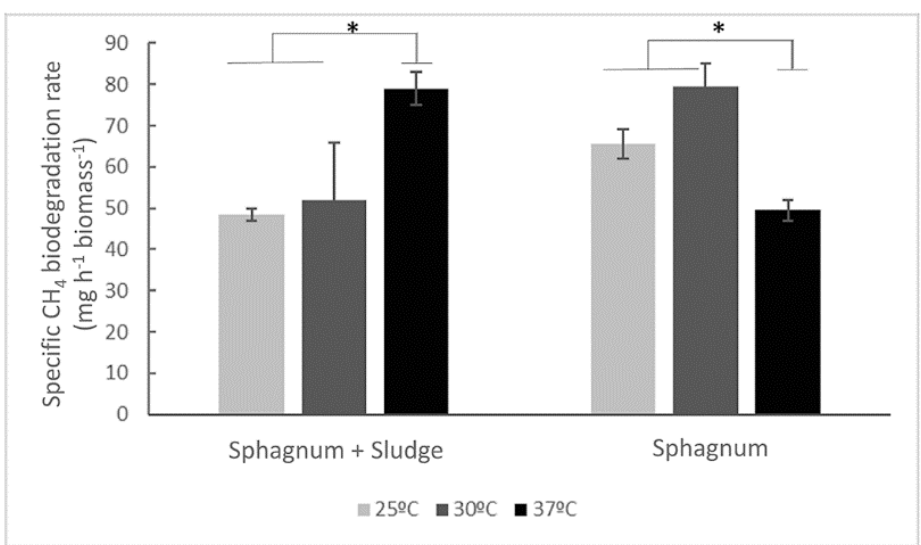

730 Figure 2. Influence of the enrichment temperature on the specific $\mathrm{CH}_{4}$ biodegradation rate

731 for the communities enriched from Sphagnum and Sphagnum + activated sludge. Error bars

732 are standard errors $(n=2)$. In both cases, no significant difference is observed between the

733 enrichment at 25 and $30{ }^{\circ} \mathrm{C}$. The biomass enriched at $37{ }^{\circ} \mathrm{C}$ showed a significant increase

734 (p-value 0.017; t-test for samples of different sizes $n=2, m=4$ ) for the mixture of Sphagnum

735 and activated sludge and a significant decrease (p-value 0.018; t-test for samples of 736 different sizes $n=2, m=4)$ for Sphagnum alone. 


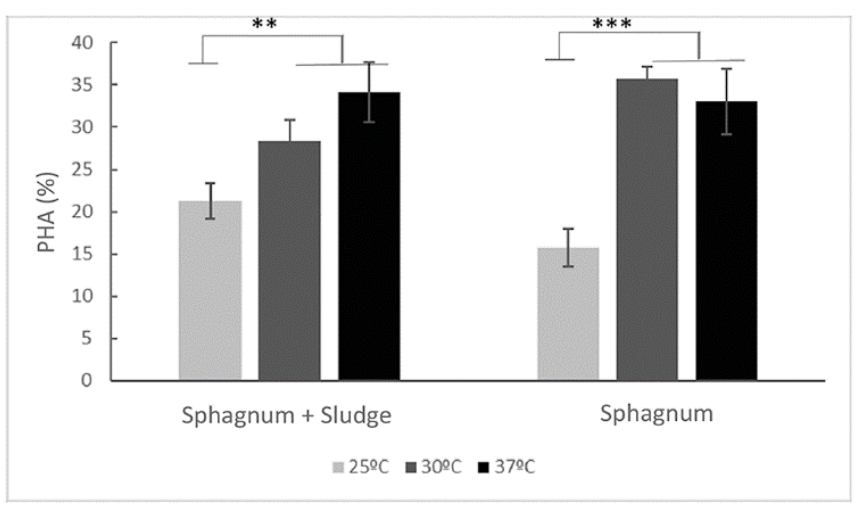

748 Figure 3. Influence of the enrichment temperature on the PHA content of the biomass 749 enriched from Sphagnum and Sphagnum + activated sludge. Error bars represent standard 750 errors $(\mathrm{n}=2)$. The same trend was observed for the mixture of Sphagnum and activated 751 sludge and Sphagnum alone. Significantly higher PHA contents were observed at 30 and 37 $752{ }^{\circ} \mathrm{C}$ compared to $25{ }^{\circ} \mathrm{C}$ (p-values of 0.00015 for Sphagnum and 0.005 for the mixture; t-test 753 for samples of different sizes $n=2, m=4)$. The differences between 30 and $37{ }^{\circ} \mathrm{C}$ were not 754 statistically significant. 


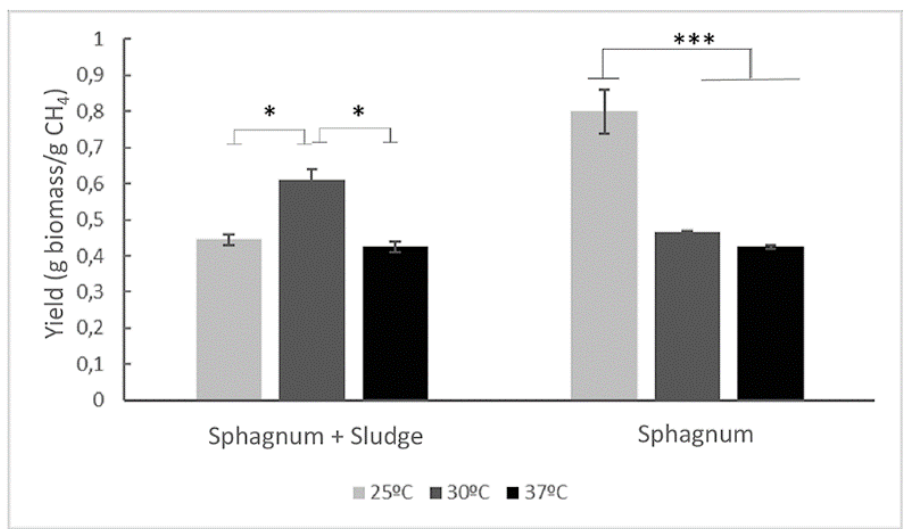

766 Figure 4. Influence of the enrichment temperature on the biomass yield on $\mathrm{CH}_{4}$ from 767 Sphagnum and Sphagnum + activated sludge. Error bars represent standard errors $(\mathrm{n}=2)$. 768 For the mixture of Sphagnum and activated sludge, the biomass enriched at $30{ }^{\circ} \mathrm{C}$ showed a 769 significantly higher yield ( $\mathrm{p}$-value 0.012 ; $\mathrm{t}$-test for samples of different sizes $\mathrm{n}=2, \mathrm{~m}=4$ ) 770 compared to the biomass enriched at 25 and $37^{\circ} \mathrm{C}$. For the Sphagnum alone a very 771 significant increased yield was observed for the biomass enriched at $25{ }^{\circ} \mathrm{C}$ (p-value 7720.00097 ; t-test for samples of different sizes $n=2, m=4)$. 


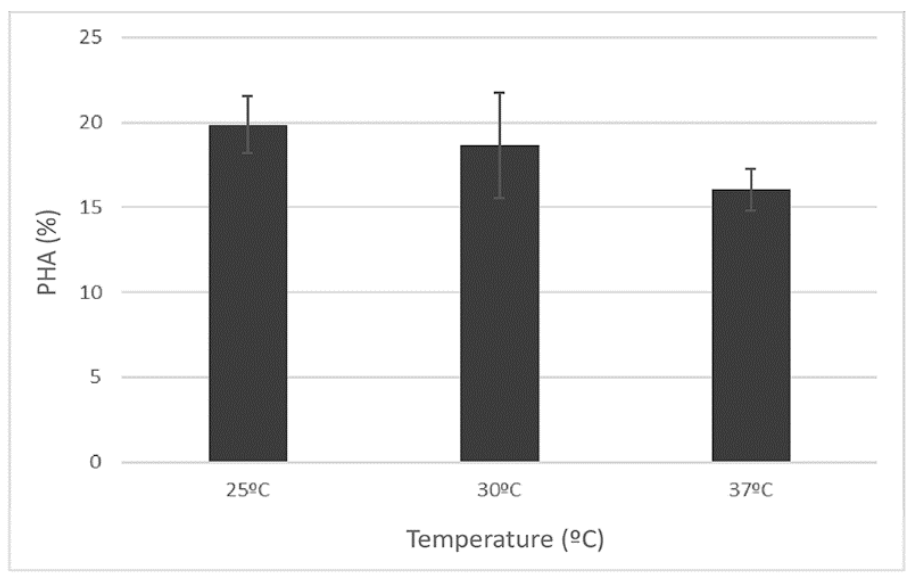

784 Figure 5. Influence of the temperature during the accumulation phase on the PHB content 785 of the biomass enriched from Sphagnum at $25^{\circ} \mathrm{C}$ under nitrogen starvation at 25,30 and 37 $786{ }^{\circ} \mathrm{C}$, respectively. Error bars are standard errors $(n=2)$. 